\title{
Interferon Beta-secreting Mesenchymal Stem Cells
}

National Cancer Institute

\section{Source}

National Cancer Institute. Interferon Beta-secreting Mesenchymal Stem Cells. NCI

Thesaurus. Code C123724.

Human autologous mesenchymal stem cells (MSCs) harvested from the bone marrow

of healthy individuals and transduced with a retroviral vector encoding the human

cytokine interferon beta (IFNb), with potential immunomodulating and antineoplastic

activities. Upon administration of IFNb-secreting MSCs, the cells are attracted and specifically migrate to tumor sites and become part of the tumor microenvironment. Since the MSCs express IFNb, these cells selectively deliver high levels of IFNb to the tumor site. In turn, IFNb binds to IFN-specific cell surface receptors and modulates the transcription and translation of certain genes whose protein products are involved in tumor cell proliferation. This decreases tumor cell growth. 